\title{
Direct evidence for implanted Fe on substitutional Ga sites in GaN
}

\author{
U. Wahl, A. Vantomme, and G. Langouche \\ Instituut voor Kern- en Stralingsfysica, University of Leuven, Celestijnenlaan 200 D, B-3001 Leuven, Belgium \\ J.G. Correia \\ CERN-EP, CH-1211 Geneva 23, Switzerland, and ITN, Estrada Nacional 10, P-2685 Sacavém, Portugal \\ L. Peralta \\ LIP and FCUL, Avenida Elias Garcia 14-1, P-1000-149 Lisbon, Portugal
}

The ISOLDE collaboration

CERN-EP, CH-1211 Geneva 23, Switzerland

(Received 9 October 2000; accepted for publication 28 March 2001)

\begin{abstract}
The lattice location of iron in thin-film, single-crystalline hexagonal GaN was studied by means of the emission channeling technique. Following $60-\mathrm{keV}$ room-temperature implantation of the precursor isotope ${ }^{59} \mathrm{Mn}$ at a dose of $1.0 \times 10^{13} \mathrm{~cm}^{-2}$ and annealing up to $900^{\circ} \mathrm{C}$, the angular distribution of $\beta^{-}$particles emitted by the radioactive isotope ${ }^{59} \mathrm{Fe}$ was measured by a position-sensitive electron detector. The $\beta^{-}$emission patterns around the [0001], [1102], [1101] and [2113] directions give direct evidence that the majority of Fe (80\%) occupies substitutional Ga sites.
\end{abstract}

It is well known that iron on substitutional III sites in the cubic III-V semiconductors such as GaAs, GaP or InP acts as a deep acceptor [1]. The most prominent example with respect to applications is $\mathrm{InP}$, where doping with $\mathrm{Fe}$ is used to produce semi-isolating material. Much less is known about $\mathrm{Fe}$ in the hexagonal III-V semiconductor GaN. Semi-isolating GaN would be useful, e.g., in hightemperature, high-power applications [2,3].

In an early investigation of the photoluminescence (PL) behavior of 35 elements implanted into GaN [4], merely damage-related luminescence around $2.15 \mathrm{eV}$ was observed following the implantation of $\mathrm{Fe}\left(5 \times 10^{18} \mathrm{~cm}^{-3}\right)$. However, this study only reported PL measurements in the energy range 1.5-3.6 eV. On the other hand, GaN layers grown by vapor phase epitaxy, which would normally be low-resistivity $n$-type, showed semi-isolating behavior if they contained high levels (up to $6.5 \times 10^{18} \mathrm{~cm}^{-3}$ ) of Fe [5]. Considerably later [6] a sharp PL peak at $1.299 \mathrm{eV}$ was discovered in the same samples used in the earlier studies of Ref. [5]. By means of optically detected magnetic resonance [6] this PL peak could be related to an electron spin resonance signal which exhibited the symmetry properties expected for $\mathrm{Fe}^{3+}$ on substitutional $\mathrm{Ga}$ sites in hexagonal GaN [6-8]. From PL excitation spectroscopy studies it was suggested that the deep acceptor level $\mathrm{Fe}^{3+/ 2+}$ is located 2.5$2.6 \mathrm{eV}$ above the valence band edge $E_{\mathrm{V}}[6,9,10]$. However, more recent experiments have given evidence that this level lies much closer to the conduction band at $E_{\mathrm{V}}+3.17$ $\mathrm{eV}$ [11].

To date, Fe has been found to be a frequent contaminant in GaN thin films grown by metal organic vapor phase epitaxy (MOVPE), hydride vapor phase epitaxy (HVPE) [9,12], and by the sublimation sandwich method with typical Fe concentrations around $10^{17}-10^{18} \mathrm{~cm}^{-3}[7,8]$. On the other hand, attempts to intentionally produce $\mathrm{Fe}$ deep centers by doping during growth or by means of ion implantation have not been very successful $[3,13,14]$. While GaN layers implanted with $\mathrm{Fe}$ up to $10^{19} \mathrm{~cm}^{-3}$ showed high sheet resistivity $\left(10^{9}-10^{10} \Omega / \square\right.$ in the asimplanted state and $10^{10}-10^{12} \Omega / \square$ following moderate annealing), the resistivity decreased considerably upon annealing to $900^{\circ} \mathrm{C}[3,14]$. Hence the semi-isolating properties must have been due to damage-related defects rather than electrically active deep Fe centers. The study of the lattice sites of implanted Fe may therefore help to clarify the processes, which hinder its electrical activation.

In this letter we report on the lattice location of ion implanted $\mathrm{Fe}$ in thin film, single-crystalline hexagonal GaN using the emission channeling technique [15]. The angular distribution of $\beta^{-}$particles emitted by the radioactive isotope ${ }^{59} \mathrm{Fe}\left(t_{1 / 2}=44.6 \mathrm{~d}\right)$ was monitored by a position-sensitive electron detector following room temperature implantation of the precursor isotope ${ }^{59} \mathrm{Mn}\left(t_{1 / 2}=4.6 \mathrm{~s}\right)$ at a dose of $1.0 \times 10^{13} \mathrm{~cm}^{-2}$ and annealing up to $900^{\circ} \mathrm{C}$. The sample was a commercially available GaN film of $1-2 \mu \mathrm{m}$ thickness grown on sapphire. Implantations of $60 \mathrm{keV}$ ${ }^{59} \mathrm{Mn}^{+}$ions were performed at the ISOLDE on-line isotope separator facility at CERN. ISOLDE provides clean, massseparated beams of radioactive $\mathrm{Mn}$ isotopes, which are produced by means of $1.4-\mathrm{GeV}$ proton-induced nuclear fission from $\mathrm{UC}_{2}$ targets and recently developed chemically selective laser ion sources [16]. During the $\beta^{-}$decay of ${ }^{59} \mathrm{Mn}$ (endpoint energies $4.4 \mathrm{MeV}$ and $4.8 \mathrm{MeV}$ ) the ${ }^{59} \mathrm{Fe}$ atom receives a nuclear recoil around $200 \mathrm{eV}$, which assures that it is reimplanted and hence that its lattice position is not influenced by the previous site of ${ }^{59} \mathrm{Mn}$. Emission channeling patterns from ${ }^{59} \mathrm{Fe}$ were extracted from the $\beta^{-}$energy window above $50 \mathrm{keV}$ up to the endpoint energy of $461 \mathrm{keV}$. Corrections for electrons backscattered into the detector were implemented by subtracting a flat background from every pattern. We have quantified the backscattering contribution by means of simulations using the 


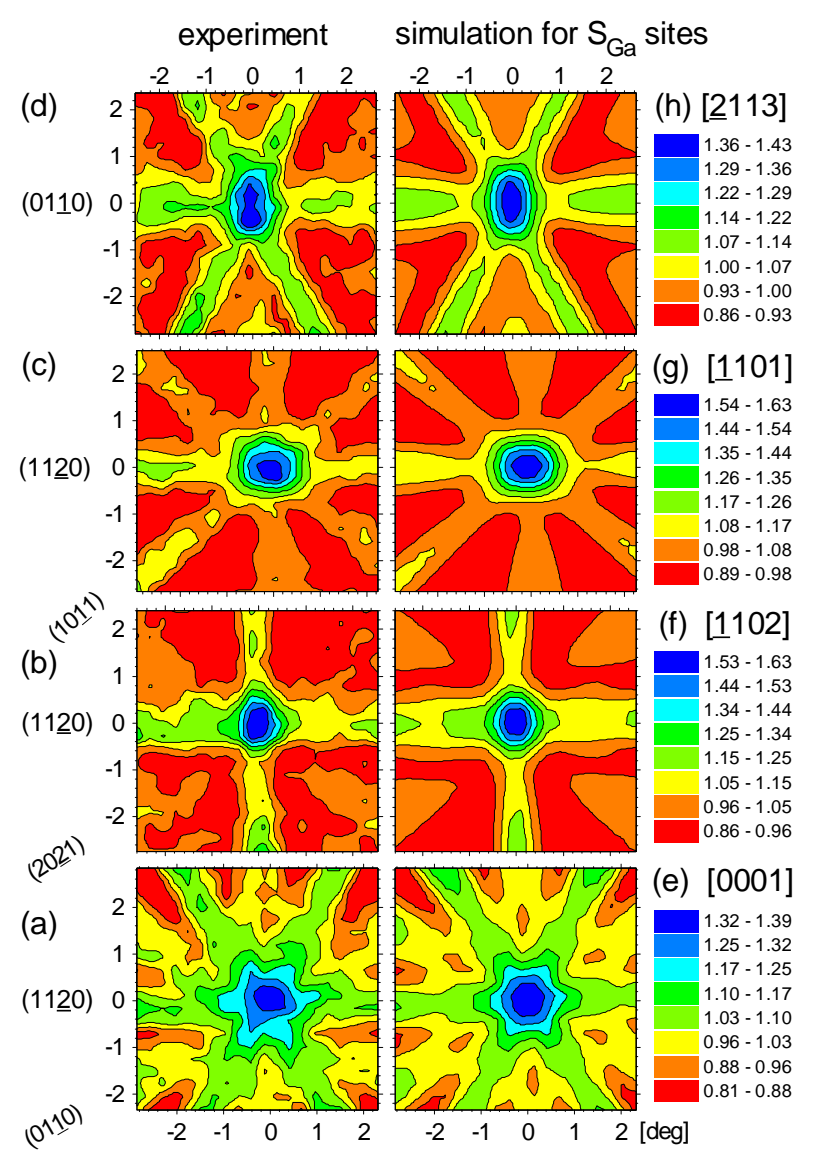

FIG. 1. Angle-dependent $\beta^{-}$emission yields from ${ }^{59} \mathrm{Fe}$ in $\mathrm{GaN}$ around the [0001] (a), [1102] (b), [1101] (c) and [2113] (d) axes. The patterns were recorded following annealing at $200^{\circ} \mathrm{C}(\mathrm{c}, \mathrm{d})$, $600^{\circ} \mathrm{C}$ (a) and $800^{\circ} \mathrm{C}$ (b). (e)-(h): best fits of simulated channeling patterns for $\mathrm{S}_{\mathrm{Ga}}$ sites to the experimental yields.

EGS4 code [17], taking into account the elemental composition and geometrical features of the $\mathrm{GaN}$ film, the $\mathrm{Al}_{2} \mathrm{O}_{3}$ substrate, the Mo sample holder and the stainless steel vacuum chamber [18].

In order to identify the lattice sites of $\mathrm{Fe}$, we have compared the experimental channeling yields to simulated patterns for ${ }^{59} \mathrm{Fe}$ emitter atoms on substitutional $\mathrm{Ga}$ sites $\mathrm{S}_{\mathrm{Ga}}$, substitutional $\mathrm{N}$ sites $\mathrm{S}_{\mathrm{N}}$, bond-centered sites both within and off the c-axis (abbreviated as BC-c and BC-o), anti-bonding sites AG-c, AN-c, AG-o and AN-o, the "hexagonal" sites $\mathrm{HG}$ and $\mathrm{HN}$, and the so-called $\mathrm{T}$ and $\mathrm{O}$ sites. Note that the $\mathrm{T}$ and $\mathrm{O}$ sites are positions which are centered in the wide-open interstitial regions of the wurtzite lattice. Details on the simulation calculations, which were carried out using the "many beam" approach, as well as the location of the above-mentioned sites within the GaN lattice, can be found in Ref. [18].

Figure 1(a) [19] shows the [0001] $\beta^{-}$emission channeling pattern from the implanted $\mathrm{GaN}$ thin film following an annealing sequence up to $600^{\circ} \mathrm{C}$. The channeling effects along the $c$ axis and the major crystal planes are evidence that the majority of ${ }^{59} \mathrm{Fe}$ atoms occupy sites which are located within the $c$-axis atomic rows. The best two-fraction fit of the theoretical yields to the experimental data is shown in Fig. 1(e) and corresponds to $86 \%$ of $\mathrm{Fe}$ atoms along the $c$ axis, and $14 \%$ on random (R) sites, which are

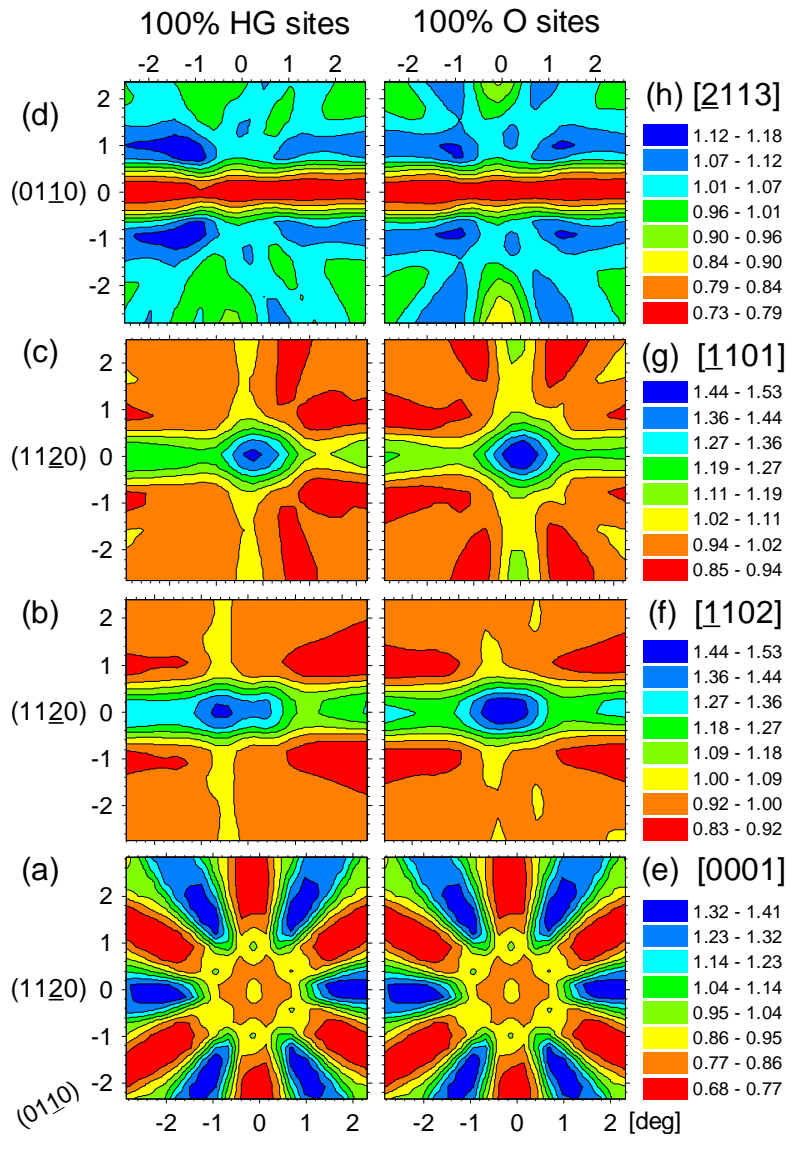

FIG. 2. Simulated channeling patterns for $100 \%$ of emitter atoms on $\mathrm{HG}$ sites [(a)-(d)] and $\mathrm{O}$ sites [(e)-(f)]. The orientation and angular resolution has been chosen so as to match the experimental patterns of Fig. 1. Note that the $c$ axis patterns of HG sites (a) and $\mathrm{O}$ sites (e) are identical.

characterized by an isotropic emission yield. However, since $S_{\mathrm{Ga}}$ and $\mathrm{S}_{\mathrm{N}}$ as well as AG-c, AN-c, BC-c and T sites are all located within the $c$ axis, considering $c$-axis patterns alone does not provide unambiguous lattice site identification and additional crystal directions must be taken into account. Suitable directions in order to discriminate these sites are the [1102], [1101] and [2113] axes [18]. The emission channeling patterns of these three directions are shown in Figs. 1(b), (c) and (d). In all cases a combination of substitutional $\mathrm{Ga}$ sites and random sites provided the best two-fraction fit. Figures 1(f), (g) and (h) show the best fits to the [1102], [1101] and [2113] patterns, corresponding to $83 \%, 73 \%$ and $84 \%$ of $\mathrm{Fe}$ on $\mathrm{S}_{\mathrm{Ga}}$, respectively.

In order to illustrate that interstitial sites are responsible for emission patterns which are distinctively different from substitutional Ga sites, Figs. 2 (a-d) show the theoretical patterns for $100 \%$ of emitter atoms on HG sites, and Figs. 2 (e-h) for $100 \%$ on O sites. From a comparison of the simulated patterns with the experimental results of Figs. 1 (a-d) it is clear that large fractions of Fe on HG or $\mathrm{O}$ sites can be ruled out. However, fractions of $8(4) \%$ of $\mathrm{Fe}$ atoms on $\mathrm{HG}$ (Ga-type "hexagonal") or 5(3)\% on O-type interstitial sites would be well in accordance with the experimental data, leading to an average improvement in the chi square of fit around $2.5(3) \%$ and $1.0(3) \%$ for all patterns. On the other hand, contributions from substitutional 


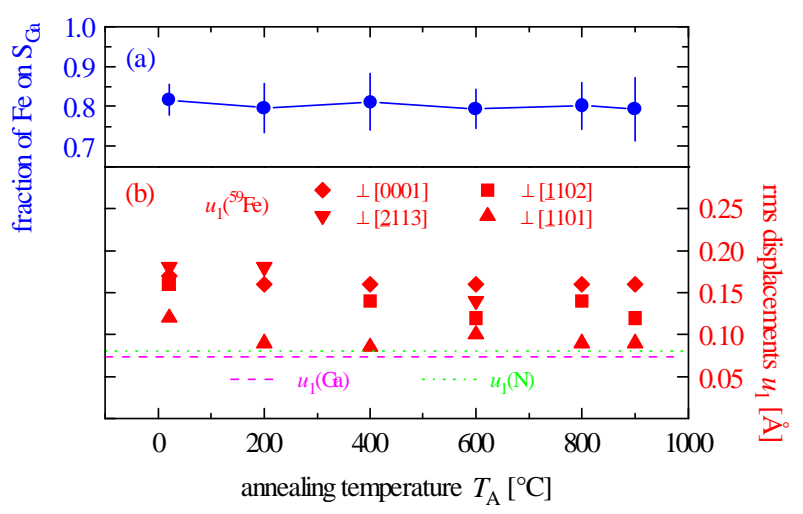

FIG. 3. Fraction of $\mathrm{Fe}$ on substitutional Ga sites (a) and its room temperature rms displacements perpendicular to the indicated crystal directions (b) following isochronal (10 min) annealing steps. The dashed and dotted lines indicate the room temperature vibration amplitudes of $\mathrm{Ga}$ and $\mathrm{N}$ atoms.

$\mathrm{N}$ sites, which also exhibit characteristic channeling patterns [18], must be very small. Fits, where Fe on both $S_{\mathrm{Ga}}$ and $S_{\mathrm{N}}$ sites were allowed, resulted in fractions on $S_{\mathrm{N}}$ sites of less than 5\% with insignificant improvements in the chi square of fit. Allowing for $\mathrm{Fe}$ on other interstitial sites such as $\mathrm{H}_{\mathrm{N}}, \mathrm{BC}$ or $\mathrm{T}$, etc also did not significantly improve the quality of fit.

Annealing the sample at $200^{\circ} \mathrm{C}, 400^{\circ} \mathrm{C}, 600^{\circ} \mathrm{C}, 800^{\circ} \mathrm{C}$ and $900^{\circ} \mathrm{C}$ did not result in substantial changes in the fraction of $\mathrm{Fe}$ on $\mathrm{S}_{\mathrm{Ga}}$ sites [Fig. 3 (a)]. This is the reason why in Fig. 1 we combined channeling patterns measured after different annealing temperatures but with best statistics. Figure 3 (b) shows the room-temperature root mean square (rms) displacements of Fe from the perfect substitutional Ga positions measured after the different annealing steps. As can be seen the rms Fe displacements, except perpendicular to the [1101] direction, are clearly bigger than the vibration amplitudes of $\mathrm{Ga}$ and $\mathrm{N}$ atoms. This suggests that $\mathrm{Fe}$ is slightly displaced from the Ga sites in a specific crystal direction close to the [1101] axis. With increasing annealing temperature, the rms displacements of $\mathrm{Fe}$ only show a slight tendency to decrease.

The maximum concentration of $\mathrm{Fe}$ in the peak of the implantation profile in our study, $6.5 \times 10^{18} \mathrm{~cm}^{-3}$, is comparable to the value of $10^{19} \mathrm{~cm}^{-3}$ in Refs. [3,14]. Since our experiments show that around $80 \%$ of implanted $\mathrm{Fe}$ atoms are incorporated on substitutional Ga sites, the absence of deep Fe acceptors in the electrical measurements of Refs. $[3,14]$ cannot be caused by Fe occupying non-substitutional lattice sites. We rather suggest that its electrical activation requires comparably high annealing temperatures (around $1100^{\circ} \mathrm{C}$ ) as the activation of ion-implanted shallow $p$ - or $n$ type dopants such as $\mathrm{Mg}, \mathrm{Ca}$ or $\mathrm{Si}$ [2]. The reasons why such high annealing temperatures are required, might be complexes of the implanted atoms with lattice defects.

Summarizing, we have given direct evidence that $\mathrm{Fe}$ is mainly incorporated on substitutional Ga sites following room temperature ion implantation. Fractions of $\mathrm{Fe}$ on other lattice sites must be small, with the possible exception of $\mathrm{HG}$ or $\mathrm{O}$ sites. Annealing the implanted sample up to $900^{\circ} \mathrm{C}$ did not affect the substitutional $\mathrm{Fe}$ fraction. Ex- cluding $\mathrm{H}, \mathrm{Li}$ and $\mathrm{Na}$, which partially occupied interstitial sites [20, 21], so far most implanted atoms ( $\mathrm{Si}, \mathrm{Ca}, \mathrm{Sr}$, In, $\mathrm{Hf}$, and rare earths) were found to substitute for $\mathrm{Ga}$ atoms in $\mathrm{GaN}[18,21-24]$. In that respect, implanted $\mathrm{Fe}$ forms no exception. Lattice location results for possible $\mathrm{N}$-site impurities such as $\mathrm{O}, \mathrm{P}$ or As, however, have not been reported so far.

This work was partially funded by the TMR-LSF program of the European Union, and by the FCT, Portugal, through project CERN/c/FIS/15180/99.

[1] S.G. Bishop, in Deep Centers in Semiconductors, edited by S. Pantelides, Gordon and Breach, New York (1985).

[2] S.J. Pearton, J.C. Zolper, R.J. Shul, and F. Ren, J. Appl. Phys. 86, 1 (1999).

[3] X.A. Cao, S.J. Pearton, G.T. Dang, A.P. Zhang, F. Ren, R.G. Wilson, and J.M. Van Hove, J. Appl. Phys. 87, 1091 (2000).

[4] J.I. Pankove and J.A. Hutchby, J. Appl. Phys. 47, 5387 (1976).

[5] B. Monemar and O. Lagerstedt, J. Appl. Phys. 50, 6480 (1979).

[6] K. Maier, M. Kunzer, U. Kauffmann, J. Schneider, B. Monemar, I. Akasaki and H. Amano, Mat. Sci. Forum 143-147, 93 (1994).

[7] R. Heitz, P. Thurian, I. Loa, L. Eckey, A. Hoffmann, I. Broser, K. Pressel, B.K. Meyer, and E.N. Mokhov, Appl. Phys. Lett. 67, 2822 (1995).

[8] P.G. Baranov, I.V. Ilyin and E.N. Mokhov, Sol. State Comm. 101, 611 (1997).

[9] J. Baur, K. Maier, M. Kunzer, U. Kauffmann, J. Schneider, H. Amano, I. Akasaki, T. Detchprohm and K. Hiramatsu, Appl. Phys. Lett. 64, 857 (1994).

[10] J. Baur, K. Maier, M. Kunzer, U. Kauffmann, and J. Schneider, Appl. Phys. Lett. 65, 2211 (1994).

[11] R. Heitz, P. Maxim, L. Eckey, P. Thurian, A. Hoffmann, I. Brosr, K. Pressel, and B.K. Meyer, Phys. Rev. B 55, 4382 (1997).

[12] J. Baur, U. Kauffmann, M. Kunzer, J. Schneider, H. Amano, I. Akasaki, T. Detchprohm and K. Hiramatsu, Appl. Phys. Lett. 67, 1140 (1995).

[13] K. Pressel, S. Nilsson, R. Heitz, A. Hoffmann, and B.K. Meyer, Appl. Phys. Lett. 79, 3214 (1996).

[14] G. Dang, X.A. Cao, F. Ren, S.J. Pearton, J. Han, A.G. Baca, R.J. Shul and R.G. Wilson, MRS Internet J. Nitride Semicond. Res. 5S1, W11.68 (2000).

[15] H. Hofsäss and G. Lindner, Phys. Rep. 210, 121 (1991).

[16] V.N. Fedoseyev et al, Nucl. Instr. Meth. B 126, 88 (1997).

[17] W.R. Nelson, H. Hirayama, and D.W.O. Rogers, The EGS4 Code System, SLAC-Report-265, Dec. 1985; http://www.slac.stanford.edu/pubs/slacreports/slac-r-265.html

[18] U. Wahl, A. Vantomme, G. Langouche, J.P. Araújo, J.G. Correia, L. Peralta, and the ISOLDE collaboration, J. Appl. Phys. 88, 1319 (2000).

[19] See EPAPS document No ........ for three color figures [Figs. 1-3].

[20] W.R. Wampler and S.M. Myers, MRS Internet J. Nitride Semicond. Res. 4S1, G3.73 (1999).

[21] C. Ronning et al, J. Appl. Phys. 87, 2149 (2000).

[22] H. Kobayashi and W.M. Gibson, Appl. Phys. Lett. 73, 1406 (1998).

[23] H. Kobayashi and W.M. Gibson, Appl. Phys. Lett. 74, 2355 (1999).

[24] E. Alves, M.F. da Silva, J.G. Marques, J. Soares and K. Freitag, Mater. Sci. Eng. B 59, 207 (1999). 